\title{
LOS JUDÍOS MALLORQUINES EN EL COMERCIO Y EN LAS REDES DE INTERCAMBIO VALENCIANAS Y MEDITERRÁNEAS DEL MEDIEVO
}

\author{
Jorge Maíz Chacón ${ }^{1}$ \\ UNED - C.A. ILLES BALEARS
}

Resumen:La comunidad judía de Mallorca tuvo un protagonismo comercial muy destacado en el Mediterráneo Occidental, sobre todo en la ruta económica con el Norte de África durante el siglo XIV. En este trabajo, a través de la rica documentación notarial mallorquina y una revisión historiográfica, se examina la formación y desarrollo de estas redes de intercambio a partir de las estrategias mercantiles de los operadores hebreos.

Palabras Clave: judíos, comercio marítimo, Mallorca, Norte de África, Mediterráneo Occidental, siglo XIV.

Abstract: The jewish community of Mallorca played an important role regarding the trade in the western Mediterranean, above all the economic route with the North of Africa during the XIV century. In this work, through the valuable notarial documentation of Mallorca and a historiographic review, it is examined the formation and development of these exchange networks starting from the commercial strategies of the hebrew operators.

Keywords: jews, maritime commerce, Mallorca, North of Africa, western Mediterranean, XIV century.

\section{INTRODUCCIÓN}

En el presente estudio, analizamos la presencia, organización y continuidad de los comerciantes judíos del reino de Mallorca durante el siglo XIV en las costas

\footnotetext{
1.jmaiz@palma.uned.es
} 
valencianas y en el Mediterráneo Occidental. Las fuentes documentales, evidencian una activa presencia de judíos mallorquines en diversas zonas; en este texto abordamos la organización de los viajes, la tipología y las consecuencias de los mismos para el conjunto de la economía y la sociedad balear, así como para las comunidades con las que entran en contacto. Los judíos establecidos en estos territorios, conformarán un complejo sistema de intercambios y redes redistributivas a lo largo del Mediterráneo medieval.

Durante la baja edad media, las Baleares se convierten en una excelente base que interactúa en la redes del comercio a gran escala ${ }^{2}$. Así, desde Perpiñán hasta Argel y de Génova a Granada pasando por Valencia, la plataforma isleña será escala cuasi obligada de un innumerable número de mercaderes y mercancías. Muchos de éstos, aprovecharan los lazos familiares y comerciales cuyo sujeto en común será el individuo o clan judío establecido -principalmente- en el call de Palma. Progresivamente, la iniciativa comercial de la Corona de Aragón será cambiante; en muchas ocasiones el eje Valencia-Mallorca se convertirá en el más dinámico. Al iniciarse el siglo XIV, el Norte de África y el Reino de Granada ofrecerán toda una seria de redes comerciales que se articulan con las Baleares y el Reino de Valencia, administrando- por encima de religiones - un conglomerado comercial judío, cristiano y musulmán, que evidentemente se someterá a las controversias de unos mares inciertos y políticamente inestables. De todos modos, sería injusto menospreciar el papel substancial que ejercen los negociantes catalanes, un flujo que se fundamenta en la mejora de las relaciones y en la existencia de la base mallorquina anteriormente inexistente.

Por su parte, en la ciudad de Valencia, se muestra una preponderancia de la comunidad musulmana y cristiana frente al mercader de origen judaico en las zonas magrebíes y nazaríes ${ }^{3}$. Desde el reino de Valencia, se produce un proceso de articulación y venta de productos en sus territorios fronterizos y hacia zonas del interior que calificamos como de paso, productos que se dirigen especialmente hacia Murcia, Granada, Almería y otras zonas del interior levantino ${ }^{4}$. No

2. Tudela i Villalonga, Ll., Catalunya, Mallorca i Gènova (1336-1349): economia i política, El Tall, Palma, 2005.; Maíz Chacón, J., Tudela Villalonga, Ll., «Els mercaders jueus mallorquins a meitat segle XIV», en XVIII Congreso de Historia de la Corona de Aragón, Universitat de València - Fundació Jaume II el Just, Valencia, 2005, pp. 1129-1148.

3. Hinojosa Montalvo, J., «Las actividades mercantiles de los judíos saguntinos. De Valencia a Granada y Berbería», en Arse. Boletín Anual de Centro Arqueológico Saguntino, 35, 2001, pp. 101-132; ver también el reciente estudio de Soler Milla, J.L., «Comercio musulmán versus comercio cristiano: la actividad de los mercaderes mudéjares y la producción de las aljamas sarracenas. Valencia, primera mitad del siglo XIV», en Anales de la Universidad de Alicante, Historia Medieval, 14, Alicante, 2003-2005, en prensa.

4. García Marsilla, J. V., «Puresa i negoci. El paper dels jueus en la producció i comercialització de queviures a la Corona d'Aragó», en Revista d'Història Medieval, 4, Valencia, 1993, pp. 161-182. 
olvidemos que en los territorios del histórico reino medieval de Mallorca los musulmanes libres establecidos en la isla eran minoría y que los hebreos -desde la misma conquista de 1229- participan activamente en la vida económica y también política del nuevo y emergente territorio. Un enclave político pero que en la práctica se convierte en una plataforma comercial, a medio camino entre la Corona de Aragón y el Magreb y en el que acontecerá una mayoría mercantil hebrea procedente de diversos territorios y que establece durante el siglo xiII y XIV un excelente centro operativo con territorios limítrofes.

Para el desarrollo de dichas actividades, los judíos valencianos y mallorquines, utilizarán las comunicaciones y relaciones que se están estableciendo de manera permanente. En este sentido, en el caso de la antigua Madina Mayurqa, se formularan pequeñas redes hacia el interior de Mallorca cuyos excelentes enlaces comerciales se encargarán de colocar los productos, situación que se configurará también hacia las zonas rurales del nuevo reino valenciano. Ya hemos establecido cierta importancia en el proceso de conquista, colonización y reparto del nuevo reino cristiano de Mallorca ${ }^{5}$, por ello y por toda una serie de elementos, las Baleares irán advirtiendo un proceso en el siglo xIII, cuya culminación será determinante para el esplendor comercial y económico de ciertas familias judías en el último tercio de dicha centuria y en la primera mitad del siglo XIV. En determinados lugares, las entidades judías se convierten en una importante fuente de ingresos para la economía de la Corona, su continuidad operativa será motivo de cierto interés por parte de los administradores políticos. Así por ejemplo, la no aplicación de la lezda a los judíos de Mallorca mediante un privilegio de noviembre de $1325^{6}$, otorgará de facto los mismos derechos a los judíos que a los ciudadanos de Mallorca y como consecuencia de ello generará ventajas comerciales que sin duda no hubieran ocurrido con dicho gravamen.

\section{LOS OBJETOS: MERCANCÍAS Y RUTAS}

La variada y rica documentación conservada nos muestra un panorama comercial muy heterogéneo. Los operadores mallorquines, valencianos y norteafricanos no serán ahora los primeros en establecer relaciones comerciales dinámicas. Ya desde el siglo XII, catalanes y aragoneses aparecen en la zona adquiriendo lana, esclavos y otros productos. Dufourcq por su parte señaló algunas diferen-

\footnotetext{
5. Maíz Chacón, J.: «Política, economía y fiscalización de un espacio urbano. El establecimiento de la aljama de los judíos en la Mallorca cristiana», en Espacio, Tiempo y Forma. Serie III. Historia Medieval, 17, Madrid, 2004, pp. 381-397.

6. Pons, A., Los judios del reino de Mallorca durante los siglos XIII y XIV, 2 vols. Palma de Mallorca, 1984, p. 115.; Assis, Yom Tov., The golden age of aragonese jewry. Community and Society in the Crown of Aragon, 1213-1327, The Littman Library of Jewish Civilisation, London-Oregon, 1997.
} 
cias y evoluciones en este mercadeo, pues en sus estudios nos adelantaba la importancia del Magreb como abastecedora de cereales y como potenciadora de los centros comerciales de la Corona de Aragón, quienes en muchos casos habrían puesto en su espacio geográfico gran parte de sus inversiones económicas?

Por su parte, María Dolores Pérez, argumentaba que el puerto mallorquín -en relación con las bases magrebíes- poco se diferenciaría de los valencianos. Completando la extensa lista de productos y sus variedades concretó que serían la lana y el cereal los principales objetos de mercadeo. De la misma manera, los responsa conservados del rabino Simón Ben Tsëmakh Duran ${ }^{8}$ evidencian esta existencia de las exportaciones. De hecho, cita que la mayoría de judíos establecidos en el Norte de África se ganaban la vida mercadeando con vecinos o entre ellos, entre estos productos destaca la importación de vino valenciano y mallorquín, insistiendo en la posibilidad de diferenciarlos 9 . Productos que se completarían con ropas procedentes de otros lugares del continente europeo. Por su parte, esta misma fuente nos habla de la exportación norteafricana de uva de Bugía y cereal de Honein, Tenes y Tremecén.

Tampoco era extraño el mercadeo de vino y productos derivados entre las zonas valenciana y mallorquina, actividad que se solía complementar con otras comandas en los mismos viajes. Por ejemplo, en diciembre de 1353 Isaac Holex tendría una comanda del judío mallorquín Jucef Salomón, cuyos bienes serían dirigidas por la coca de Bernat Sarigie hacia Valencia y desde allí a Denia y Alger $^{10}$. Para nosotros, parece bastante habitual la utilización de rutas portuarias en el mercadeo de productos, utilizando una y otra vez los puertos de escala no sólo para vender los productos allí demandados sino también para abastecerse en los mercados locales con nuevo productos con unos requerimientos más o menos constantes. Así, el patrón de barca de Cullera Raimundo Roche, tenía comandas de Scongosa Lamoni (judío de Algeciras) por valor de 17 libras que se correspondían con 12 botas de vino y 13 quintales de pausquis que vendrían de Cullera hasta Mallorca ${ }^{11}$. De la misma manera ocurre en 1353 con Mosse Almaciri (judío de Mallorca) que con una comanda para dirigirse a Denia y Tedelis ${ }^{12}$ o Mosse

\footnotetext{
7. DufourcQ, Ch-E., «La place du le Maghrib dans l'expansion de la Couronne d'Aragon: La route maghribine par rapport a celle des iles et des epices», en II Congreso Internacional de Estudios sobre las Culturas del Mediterráneo Occidental, Barcelona, 1978, pp. 271-279.

8. Epstein, I., Les responsa del rabi Simó Ben Tsémakh Duran: una Font per a la història dels jueus del nord d'África, Lleonard Muntaner, Palma, 2001.

9. Ibídem, p. 60 y 63.

10. Archivo Capitular de Mallorca, Notari Francesch Balle, n. ${ }^{\circ} 14.568$, f. 196v-197.

11. Archivo Capitular de Mallorca, Notari Pere de Cumba, n. ${ }^{\circ}$ 14.578, f. 227.

12. Ibidem, n. ${ }^{\circ} 14.578$, f. 268.
} 
Matiri, judío de Mallorca con una expedición de una coca que conducirá hasta Denia, y Hone o bien Auharanaum (Orán) ${ }^{13}$.

A mediados del siglo XIV, lo habitual sería realizar escalas entre Mallorca y Valencia como requerimiento previo al destino magrebí. La situación sería consecuencia de una mayor seguridad en la ruta y del establecimiento de operaciones económicas en común entre valencianos y mallorquines, con intereses comunes en muchos lugares del norte de África. De entre la documentación consultada, la ruta habitual solía hacer escala en Calpe o Murvedre, y de allí hacia las zonas habituales con operadores mallorquines ${ }^{14}$. Tenemos también evidencias que argumentarían a favor de una preponderancia de los judíos mallorquines en estas operaciones, siendo la escala motivo casi obligado para obtener productos y para ocupar el papel que se reseña como minoritaria dentro del judaísmo valenciano ${ }^{15}$. Los judíos del reino de Valencia no realizarían tal cantidad de operaciones y en muchas ocasiones serían substituidos por los emergentes grupos comerciales cristianos y mudéjares ${ }^{16}$. Aquí, los judíos del reino de Mallorca desempeñarían una vital labor de complemento comercial entre unos y otros, bien mediante operaciones con mercaderes judíos o con cristianos de manera indistinta en las localidades señaladas.

En este sentido, otra de las habituales escalas serían las que se realizan en el puerto de Denia. Allí Mossen Benabriam, judío de Mallorca realizaría en 1353 algunas escalas como paso previo a su viaje a Bugía, Alger o Orán ${ }^{17}$ sin especificar el motivo. Por su parte Mosse Materi, judío de Mallorca se habría comprometido con Berengario Vich (ciudadano de Mallorca) por el daño ocasionado a este último, señalando a Raimundo Sagarosi de Gandía como culpable de dichos daños y dándole a cambio 100 jarras de vino de Denia 500 cafices de atzabib albi, 10 carricas de alquene, hasta 250 quintarias de garrovarum, las cuales vos debíais recibir en dicho lugar de Denia, para ir a Mallorca. Indicando

13. Archivo Capitular de Mallorca, Notari Pere de Cumba, n. ${ }^{\circ} 14.578$, f. 333.

14. Tómese como ejemplos el viaje del leño San Antonio. Archivo Capitular de Mallorca, Notario Pedro de Cumba, n. ${ }^{\circ} 14.580$, f. 44. O la recepción de 87 florines de oro de Maymo Ben Faraig y Dauhet Marini (judíos de Mallorca) por parte el patrón valenciano Bernardus Bovis con motivo del cambio que estos habrían realizado en Túnez, Málaga y Mallorca. Archivo Capitular de Mallorca, Notario Francesc Balle, n. ${ }^{\circ} 14.567$, f. $12-12 \mathrm{v}$.

15. Soler Milla, J.L., «Los judíos valencianos y las rutas mercantiles en el Mediterráneo bajomedieval», en Anales de la Universidad de Alicante, Historia Medieval, 15, 2006-2008. Dossier monográfico «El legado histórico de los judíos de la Corona de Aragón».

16. Hinojosa Montalvo, José: «Actividades judías en la Valencia del siglo XIV», en La ciudad hispánica durante los siglos XIII al XVI (Actas del Coloquio celebrado en La Rábida-Sevilla, 1981), II, Madrid, 1985, p. $1547-1566$.

17. Archivo Capitular de Mallorca, Notario Francesc Balle, n. ${ }^{\circ} 14.568$, f. $114 \mathrm{v}$. 
al respecto que se realizará el pago a la vuelta del viaje y que los costes así como tres sólidos por libra de lucro sería a cargo del judío palmesano ${ }^{18}$. La operación estaría relacionada con un viaje posterior a Berbería, siendo este impedido mediante mandato real quien habría emitido la orden de «que nadie podía ni debía en dichos lugares enviar algunas mercancías o bien cargar algunas mercaderías en algunas de las vasas marinas por causa de enviar a algún lugar de Barbería, ni algunas partes fuera de la dominación, con estos vasiis» ${ }^{19}$. El citado comerciante también habría tenido otras operaciones en la zona, así por ejemplo lo localizamos comerciando con ficcus de Murcia, que son vendidos a Berenguer Vichi, ciudadano de Mallorca ${ }^{20}$. Otra muestra, sería la del patrón de la coca San Antonio Bernat Noguera, quien tenía una comanda de Dauhet Bonsenyor (judío de Mallorca) por valor de 40 libras mallorquinas para dirigirse hacia Argel, Denia y Bugía ${ }^{21}$, o la realizada por Petrus de Furnis (patrón de la cocha San Vicencio) por la comanda de Jucef Salomón para un viaje hacia Cullera, Denia y de allí a Argel $^{22}$.

Sin duda, la confluencia y la versatilidad de los comerciantes mallorquines habría originado un comercio entre zonas, en ocasiones dinámico y en otras un tanto más estáticas, pero que mostraría diferencias entre dos tipos de actividades. Según Antoni Riera ${ }^{23}$, éstas se podían manifestar entre las rutas hacia el interior aprovechando las redes locales de intercambio ya establecidas, y rutas de mayor capacidad desarrolladas por grandes mercaderes cuyas actividades estarían más allá del mero comercio local de productos de primera necesidad. Evidentemente, los grandes mercaderes catalanes y genoveses ejercen un fuerte poder en las rutas del comercio internacional, aunque aquí podemos evidenciar los excelentes lazos que establecen los comerciantes hebreos procedentes o con destino en el reino de Mallorca. Sus posibilidades de adaptación a los cambios y sus diferencias entre las rutas locales y supra-locales los colocaban en un lugar privilegiado, principalmente en el Magreb, área en la que había desarrollado toda una seria de redes de dependencia e intercambio que incluía agentes comerciales, corredors de levant, embajadores y representantes de sociedades y mercaderes individuales. Las notas, incluso nos remiten a zonas de menor intercambio como podía ser Sevilla lugar en el que el mismo Salomón Xulell habría realizado viajes de

18. Ibidem, f. $159 \mathrm{v}-160$.

19. Archivo Capitular de Mallorca, Notario Pere de Cumba, n. ${ }^{\circ} 14.576$, f. $83 \mathrm{v}-84 \mathrm{v}$.

20. Archivo Capitular de Mallorca, Notario Francesc Balle, n. ${ }^{\circ}$ 14.568, f. 184.

21. Archivo Capitular de Mallorca, Notario Francesc Balle, n. ${ }^{\circ} 14.568$, f. 178-178v.

22. Archivo Capitular de Mallorca, Notario Pere de Cumba, n. ${ }^{\circ}$ 14.577, f. 231.

23. Riera Melis, A., «El comerç a la Mallorca medieval», en L'Avenç, 59, 1983, pp. 354-357. 
allí a Denia y posteriormente hacia Thanes (tierra de sarracenos) con la nave San Antonio ${ }^{24}$.

El restringido grupo de grandes mercaderes, sería inferior en número al dedicado al comercio redistributivo de productos derivados del campo y frutos se$\cos ^{25}$. Los primeros incluso serían motivo de cierta controversia, ya que según sus posibilidades estarían capacitados para comprar gran cantidad de productos a cierto precio y posteriormente revenderlos a precios mucho más elevados, bien generando una escasez en el mercado bien acaparando casi la totalidad de los mismos. Así, Yishaq ben Seset Perfet cita en un 'responsa' hacia 1388 al rabino Moseh Gabbay quien indicara dicha situación sobre la situación de las lanas que vienen a Valencia importada de diversas procedencias ${ }^{26}$.

Otra de las principales materias con cierta demanda en Mallorca es el cereal. Producto con una producción no excedentaria en los territorios privativos y que además sufrirá diversas crisis durante el siglo XIII y XIV que ofrecerán un panorama deficitario para una población que se encuentra en crecimiento constante. Ya resaltó Dufourcq ${ }^{27}$, que el Magreb era un centro importante de abastecimiento de cereal para la Corona de Aragón, principalmente para el Reino de Mallorca y de Valencia.

Por lo que respecta a la isla de Menorca, las circunstancias serían un tanto especiales. En primer lugar, los judíos isleños ofrecerían cierta dependencia con la aljama palmesana, pues en la misma se encontrarían sus órganos de representación y su ligazón durante el siglo XIII sería más que evidente. Por otro lado, las escalas de los grandes mercaderes serían menores en cantidad y reducidas casi exclusivamente al fuerte flujo mercantil existente entre Alcudia y Ciudadela. Estando por tanto en detrimento otros itinerarios comerciales más alejadas y peligrosas (rutas directas hacia Valencia o al Magreb). De la misma manera, hemos

24. Archivo Capitular de Mallorca, Notario Jaime de Aviñón, n. ${ }^{\circ}$ 14.625, f. 46.

25. Los frutos secos habrían sido estudiados por la Dra. Ferrer i Mallol en un interesante texto en el que evidencia los productos básicos de exportación de Cataluña, Valencia y Mallorca; materias que serían redistribuidas en zonas tan distintas y distantes como Italia, Inglaterra, Flandes y el Magreb. Ver, Ferrer MaLlol, M.T., «Fruita seca i fruita assecada, una especialitat de l'àrea econòmica catalana-valenciana-balear», en Anuario de Estudios Medievales, 31.2, 2001, pp. 883-943; especialmente para el Magreb, ver Soler Milla, J. L., «Relaciones mercantiles entre Valencia y el Magreb durante la primera mitad del siglo XIV», en Miscelánea Medieval Murciana, XXXVII-XXVIII, 2003-2004, Murcia, pp. 125-157.

26. Magdalena Nom De Déu, J.R., «Aspectos de la vida de los judíos valencianos reflejados en los 'responsa' de Rabí Yishaq Ben Seset Perfet (segunda mitad del siglo XIv)», en Juderías y sinagogas de la Sefarad Medieval, Universidad de Castilla la Mancha, Cuenca, 2003, pp. 156.

27. DufourcQ, Ch-E., «Liaisons maritimes et commerce catalans, majorquins et valenciens avec le Maghrib du XIIIè au XVè siècle», en Cuadernos de Historia Económica de Cataluña, XX, 1979, pp.109-118. 
recogido actividades de mercaderes valencianos con judíos menorquines ${ }^{28}$, aunque ciertamente serían menores que las actividades que proceden entre Menorca y Mallorca. En este caso se trataría de Astruch Abram judío valenciano quien se dirigiría a Menorca portando madera con el objetivo de colocarla en el mercado insular. En 1385, Samuel Sesportes, judío palmesano llevaría también hierro al puerto de Ciudadela ${ }^{29}$, o la nau de Pere Soler, Pere Olivar y Vidal de Benasay (judío) con origen en Ciudadela y cuyo destino se vería truncado por un naufragio ${ }^{30}$. Con estos ejemplos podemos pensar que dichas actividades se encargarían de completar la demanda existente en una sociedad como la menorquina con ciertas necesidades de materias primas.

Otra de las cuestiones que debemos señalar es la adaptación del mercader judío al contexto político del momento. En esta línea, muchos judíos irán estableciendo lazos comerciales con sus contactos en los distintos puertos de redistribución de productos, y del mismo modo, sabrán paralizar sus actividades o diversificarlas con la finalidad de minimizar riesgos en etapas más convulsas. El reino de Valencia y -especialmente- los territorios insulares del reino de Mallorca, gozarán en determinados momentos de una balanza comercial negativa, muchos de los productos que consume su emergente población o que se necesitan en los centros artesanales y manufactureros que se están creando no están copados con la producción local, así deberán ser adquiridos en plazas y a precios que en ocasiones serán peyorativos para las iniciativas económicas locales.

La etapa que ya hemos estudiado indica que algunos de los comerciantes judíos más importantes como Jucef Faquin ${ }^{31}$, Isaac Mahabub ${ }^{32}$ o Maimó Ben Faraig $^{33}$ fletaban bienes en el mercado mallorquín, pero procuraban diversificar

28. Archivo del Reino de Valencia, Mestre Racional, 2 (1382), f. 41: «item reebí d'en Astruch Abram per treta de quatre dobleres que trasch de la dita plaja per dur a Manorqua IIII sous». Documento citado en: RosSelló Vaquer, R., «Comerç entre València i Menorca (1381-1402), en Bolletí de la Societat Arqueològica Lul·liana, 44, 1988, pp. 171-177.

29. Archivo del Reino de Mallorca, Guiatges, 4, f. 29. Documento citado en: Rosselló Vaquer, R.: Aproximació a la història medieval de Menorca. Segle XIV (reis de Mallorques i Pere el Cerimoniòs), Consell Insular de Menorca, Mahón, 1985.

30. Archivo de la Corona de Aragón, Reg. 1.448, f. 146v. Documento citado en: Rosselló Vaquer, R., Aproximació a la història medieval de Menorca... ver también: MaYol Llompart, A., El comerç marítim entre Alcúdia i Ciutadella en la Baixa Edat Mitjana (1300-1526), Ayuntamiento de Alcudia, Alcudia, 2005.

31. Archivo Capitular de Mallorca, Anónimo, n. 14.784, f. 46v-47. En este caso se trata de la coca San Julián. La misma, contaba con dos cohopertas, 28 marineros y 7 serviciales. Jucef Faquim tendría cargamento por 100 quintarias introytum.

32. Mahabub tiene una comanda por valor de 20 libras mallorquinas con Bernardo Noguera, en forma de salarios y campaña hacia Mostaganem.

33. Archivo Capitular de Mallorca, Anónimo, n. 14.783, f. 213r: «... nos encontramos, en ingressu, por gerra de oli, la cuantía de dos sólidos, por vitreo de aquelne, la cuantía de 15 dineros, por pieza de paño, la cuan- 
pedidos. En la etapa de reintegración del reino privativo a la Corona de Aragón u otras fases de 'tensión política', la presencia de judíos en el mercadeo de la zona se concentra mediante cocas de gran capacidad hacia el Magreb ${ }^{34}$, Valencia, Mediterráneo Central ${ }^{35}$ y Granada ${ }^{36}$, aunque los viajes en cierta medida no eran todo lo habituales que solían ser. Los problemas derivados de la situación política se unían a la dificultad de establecer rutas continuas en unas etapas de palpitación marítima. De este modo, algunas de las fuentes notariales destacan ataques casi continuos a barcos con intereses comerciales, sirva de ejemplo la petición de recuperación de bienes ordenada a Antonio de Podialibus por parte de los judíos mallorquines Salomón Xulell, Jucef Faquim, Maymón Ben Arón y Jacob Benallel en los mares de Tenes ${ }^{37}$.

La documentación nos habla también de otros conflictos derivados del mercadeo con el Magreb. Así en 1345, Ramón de Cruylles de Valencia y Bernat Moster de Mallorca habrían realizado una operación ilegal de compras de lana mayores a las indicadas y en un lugar diferente al habitual ${ }^{38}$. Dicha actividad habría escapado del control tarifario de los mercaderes y sería motivo de una petición al cónsul y los mercaderes de Hona, mediante una prohibición de comprar a ningún moro, judío o cristiano lanas bajo pena de 1.000 doblas. Indica también la necesidad de apresar el barco que se dirige hacia Mallorca desde Mostaganem con la finalidad de esclarecer la situación.

La confluencia en el norte de África de las diversas rutas que comerciaban con oro se concretaba también en una fuerte demanda por parte de los operadores allí establecidos. La redes de intercambio que existirían entre las zonas magrebíes y las subsaharianas estarían monopolizadas por mercaderes de origen magrebí y supondrían cierta desigualdad en el intercambio de este producto. Los intercambios

tía asciende a dos sólidos y 6 dineros barceloneses, por bala de canabasii, la cuantía asciende a 4 sueldos. Mientras que por naulo de regreso, se encuentra, por lana de baldragnorum, la cuantía es de 4 sólidos y 6 dineros, por boquinarum, la cuantía es de 4 sueldos y 6 dineros, por quintar de coriorum, asciende a 2 sólidos y 7 dineros, por quarteria de frumenti (y no quintar), asciende a la cifra de dos sólidos y 6 dineros, mientras que por quintar de grani, la cuantía asciende a 9 sueldos, por gerra de alquitrán, asciende a 3 sólidos y 6 dineros...»

34. En varias ocasiones estas operaciones se realizan mediante convenios con mercaderes cristianos. Así sucede con los comerciantes mallorquines de origen judío: Juceff Faquin, Isaac Mahabub o Maimó ben Faraig.

35. Archivo Capitular de Mallorca, Notari Francesc Balle, n. 14.567, f. 302v. Nuevamente Jucef Faquim, habría realizado una aportación de 35 libras al viaje comercial del también judío Maymonus Bensallem en la coca Anthonii Serdani hacia Cerdeña.

36. Cateura Bennasser, P., «Notas sobre las relaciones Mallorca y el Reino de Granada», en Bolletí de la Societat Arqueológica Lul-liana, 37, 1979, pp. 151-165; DufourcQ, Ch-E., «Aspects Internationaux de Majorque durant les derniers siècles du Moyen Age», en Mayurqa, 11, 1974, pp. 5-52.

37. Archivo Capitular de Mallorca, Notario Pere de Cumba, n. ${ }^{\circ} 14.578$, f. 45-45v.

38. Archivo del Reino de Mallorca, Arxiu Històric, Governació, 441, f. 249 y ss. 
generalmente incluirían lana, cuero y productos de baja calidad, conjuntamente con los metales preciosos, mientras que se colocarían en el mercado local telas de calidad y productos manufacturados de lo más variado. La llegada de estos metales a las plazas valencianas y mallorquinas quedaba en muchas ocasiones fuera del control administrativo, ya que en mucha ocasiones la imposibilidad de batir monedas en estas zonas dirigiría los metales hacia Barcelona ${ }^{39}$.

\section{EPÍLOGO COMERCIAL}

Pensamos que debido a la importancia económica en el conjunto de la hacienda mallorquina, los grandes grupos de judíos comerciantes así como sus intereses serán motivo de protección regia bajo una u otra fórmula. Las distintas ligas comerciales creadas y las entidades económicas judías y judeocristianas así como sus operaciones serán motivo de actuación legal y judicial durante algunos de los determinantes momentos de la historia del Mediterráneo Occidental. Para M.D. López ${ }^{40}$, sería uno de los motivos por los que Martín el Humano justifica la protección ante las agresiones piráticas y otros ataques que sufre la minoría. Las sugerencias también estarían relacionadas con la finalidad de evitar una masiva migración tras el asalto de 1391 y la consecuente paralización parcial de la economía comercial, un porcentaje económico que seguirían aportando conversos pero que paulatinamente iría en declive hasta su desaparición final.

Por ello, los datos muestran una incidencia más que considerable que afectaría al comercio exterior isleño, aunque no por ello indicaría la desaparición directa de las operaciones que aquí analizamos. Después del trágico asalto al call palmesano y tras las migraciones forzadas, uno de los pilares comerciales se viene abajo y muchos operaciones bien se truncan bien cambian de operador geográfico o logístico. El pogromo -por tanto- afectaría gravemente a las transacciones comerciales del mediterráneo occidental y rompería algunos lazos comerciales entre los hebreos valencianos, mallorquines y magrebíes, siendo una muestra de una progresiva decadencia que se produce en estos ámbitos comerciales. Con posterioridad a 1391 se mantienen las actividades con los judíos y judeo-conversos pero se concentran en operadores geográficos más limitados y también se reducen a lazos empresariales familiares ${ }^{41}$. Acelerando así el proceso

39. Archivo Municipal de Valencia, G 3-8, f.181 r. (Valencia. 26, septiembre, 1405). Documento citado en: LóPez Pérez, Mª.D., La Corona de Aragón y el Magreb...

40. Archivo de la Corona de Aragón, Cancelleria, Reg. 2.264, f.143 v.-144 r. (Zaragoza. 20, agosto, 1399). Documento citado en López PÉrez, Ma.D., La Corona de Aragón y el Magreb...

41. López Pérez, M.D., «Los operadores magrebíes en la Corona de Aragón a finales del trescientos y principios del cuatrocientos: las actividades mercantiles de judíos y musulmanes norteafricanos», en XIV Congresso di Storia della Corona d'Aragona, (Sassari-L'Alghero, 1990), II, Istituto di Storia Medioevale 
que acabaría con la paulatina creación de empresas mixtas de cristianos y judíos que continuarían de una u otra manera con las operaciones; conjuntamente con los proyectos mallorquines-magrebíes ${ }^{42}$, que nos llevarían hasta la desaparición de estos agentes comerciales por las aguas mallorquinas estrictamente hebreos. Lugar que ocuparían otros sujetos con las mismas y nuevas empresas que serán las protagonistas ya del siglo Xv, etapa en la que Mallorca perdería a nuestro entender parte de su potencial en detrimento de Barcelona, Valencia y otros operadores.

-Università di Cagliari, Sassari, pp.573-598; IDEM, «El pogrom de 1391 en Mallorca y su repercusión en los intercambios comerciales con el Magreb», en I Col.loqui d'Història dels Jueus a la Corona d'Aragó, Institut d'Estudis Ilerdencs, Lleida, 1991, pp. 239-260. Ver también Hinojosa MonTALvo, J., «Los judíos en el reino de Valencia durante el siglo XV», en Anales de la Universidad de Alicante. Historia Medieval, 3, 1983, pp. 143-183.

42. Archivo del Reino de Mallorca, Protocolos Notariales, 2.466, f.106 v.-107 r. (Mallorca. 28, agosto, 1409); Ibídem, f.107 r. (Mallorca. 28, agosto, 1409); Ibídem, f.121 r. (Mallorca. 4, noviembre, 1409). 